Brown T, Wilkinson RH. Chronic recurrent multifocal osteomyelitis. Radiology 1988; 166:493-6.

Cone RO, Resnick D, Goergen TG, et al. Condensing osteitis of the clavicle. AJR 1983;141:387-8.

Eftekhari F, Jafie N, Schwegel D, Ayala A. Inflammatory metachronous hyperostosis of the clavicle and femur in children: a report of two cases, one with long-term follow-up. Skeletal Radiol 1989; 18:9-14.

Franquet T, Lecumberri F, Rivas Inaraja L, Idoate MA. Condensing osteitis of the clavicle: a report of two new cases. Skeletal Radiol 1985; 14:184-7.

Friedrich $H$. Uber ein noch nicht beschriebenes, der Perthesschen Erkrankung analoges, Krankheitsbild des sternalen Clavikelendes. Dtsch Zeitschr Chir 1924; 187:385-98.

Jones MW, Carty H, Taylor JF, Ibrahim SK. Condensing osteitis of the clavicle: does it exist? J Bone Joint Surg [Br] 1990; 72-B :464-7

\section{Reply from the authors:}

Sir

We thank Doctors Kerr and Resnick for their interest in our paper and note that they consider that condensing osteitis of the clavicle is a well-defined non-infective disorder. However, we believe, for the reasons stated in our paper that evidence for this is currently lacking.

To give an example, one reference that they use to support their argument (Cone et al 1983) appears to add the seventh and eighth cases of condensing osteitis to the literature. This is, in fact, representative of the rather unscientific attempts to introduce this new condition. In one case the history is described in reasonable detail and radiographs, an isotope bone scan and a biopsy were performed, but there was no attempt whatsoever to exclude sepsis. The second patient was reported with very scanty clinical data, plain radiography and an isotope bone scan. Sepsis does not appear to have been considered in the differential diagnosis and there was no histological examination of the lesion.

We agree with Doctors Kerr and Resnick that condensing osteitis does not exist in children. However, we refute their diagnosis of chronic multifocal osteomyelitis in our cases when there was a single non-recurrent focal lesion. Until there is more scientific proof, condensing osteitis in adults remains a very dubious diagnosis indeed.

$$
\text { M. W. JONES, MChOrth, FRCS, FRCS Ed }
$$

Lecturer in Orthopaedics

"Mallard's Flight",

7 Heron Close,

Bridge Meadow,

Leicestershire LE8 0DZ.

H. CARTY, FRCP I, FRCR Consultant Radiologist

J. F. TAYLOR, MChOrth, MD, FRCS Consultant Orthopaedic Surgeon

S. K. IBRAHIM, MRCPPath Consultant Pathologist

\section{USE OF TOURNIQUETS}

Sir,

I read with interest the paper by Salam et al (1991; 73B:86-7) and the resulting correspondence (1991; 73-B:869) concerning the complications arising from the use of tourniquets during tibial plating. The wound complications and leg swelling after tourniquet removal are almost certainly due to an ischaemic-reperfusion injury and are analogous to the situation after a successful femoropopliteal arterial by-pass.

The basis of this injury is the release of free radicals and other toxic oxygen species by activated neutrophils (Paterson et al 1989). Postoperative leg swelling after arterial surgery can be prevented by administering mannitol intraoperatively or by pretreatment with the free-radical scavenger allopurinol (Paterson et al 1991). This approach may well be of use to orthopaedic surgeons who use tourniquets for prolonged periods.

University Department of Vascular Surgery,

A. EDWARDS, FRCS Vascular Research Fellow

University Hospital of South Manchester,

Nell Lane, Manchester M20 8LR.

Paterson IS, Klausuer JM, Goldman G et al. Thromboxane mediates the ischemia-induced neutrophil oxidative burst. Surgery 1989 ; $106: 224-9$.

Paterson IS, Browning N, Hanbury A, O'Dwyer S, McCollum CN. Ischaemia and reperfusion as a cause of leg swelling following femoropopliteal by-pass. Br J Surg 1991;78:A738-9.

Salam AA, Eyres KS, Cleary J, El-Sayed HH. The use of a tourniquet when plating tibial fractures. J Bone Joint Surg [Br] 1991 ;73-B :86-7.

\section{RANDOM BLOOD SALVAGE}

Sir,

In your July issue (73-B:591-4) you published an article by Slagis et al, entitled 'Postoperative blood salvage in total hip and knee arthroplasty', with the subtitle 'A randomised controlled trial'.

The method of sampling the patients is not clear. Of the 109 patients entering the study, seven were excluded for different reasons, leaving 102 patients having arthroplasties. In the Results section the study and control groups are stated to be evenly matched for age and sex. It is a little confusing that the word 'randomised' is used in the subheading, when the total material is evenly matched for age and sex. This seems impossible without additional exclusions.

Some questions remain: was the material at any point allocated at random? If so, how was this procedure carried out? And why were the groups then evenly matched for age and sex? It seems to be of general interest that the prospective design of the study is clearly presented.

HANS FREDIN, MD, PhD

Department of Orthopaedics,

Malmő General Hospital, S-214 01 Malmö, Sweden.

Slagis SV, Benjamin JB, Volz RG, Giordano GF. Postoperative blood salvage in total hip and knee arthroplasty: a randomised controlled trial. J Bone Joint Surg [Br] 1991;73-B:591-4.

\section{Reply from the authors:}

Sir,

We write in response to the questions raised by Doctor Fredin regarding the design of our study. Our patients were randomised as follows:

1) All patients presenting for joint replacement surgery were offered participation in the study; those who agreed were then assigned a date for operation.

2) The blood salvage process was carried out only on alternate weeks. The person assigning the surgery date was 